\title{
Catalytic Synthesis of Salicylate Esters over Cordierite Honeycomb Coated with $\mathrm{Mo}$ (VI)/ZrO $\mathrm{Zr}_{2}$
}

\author{
Manjunatha Shyamsundar ${ }^{1}$, Sathgatta Zaheeruddin Mohamed Shamshuddin ${ }^{1 *}$, \\ Nabisab Mujawar Mubarak ${ }^{2}$, Srinivas Raghavendra Prathap ${ }^{1}$ \\ ${ }^{1}$ Chemistry Research Laboratory, HMS Institute of Technology, Tumkur, India \\ ${ }^{2}$ Department of Chemical Engineering, University of Malaya, Kualalumpur, Malaysia \\ Email: ${ }^{*}$ em_es@rediffmail.com
}

Received January 5, 2013; revised February 15, 2013; accepted February 24, 2013

Copyright (C) 2013 Manjunatha Shyamsundar et al. This is an open access article distributed under the Creative Commons Attribution License, which permits unrestricted use, distribution, and reproduction in any medium, provided the original work is properly cited.

\begin{abstract}
Solid acids such as $\mathrm{ZrO}_{2}$ \& Mo (VI)/ZrO $/ \mathrm{ZO}_{2}$ were coated on a honeycomb monolith by impregnation method. These catalytic materials were characterized by $\mathrm{NH}_{3}$-TPD, PXRD and SEM techniques. Salicylate esters were synthesized via transesterification of methyl salicylate with different alcohols over these catalytic materials. An excellent yield of Salicylate esters was obtained under specific reaction conditions. A correlation between the surface acidity, PXRD phase and catalytic activity of $\mathrm{Mo}(\mathrm{VI}) / \mathrm{ZrO}_{2}$ was observed. The thermally regenerated catalytic material was reused repeatedly with a consistent high yield of salicylate esters. The honeycomb coated with zirconia catalysts were found to be economical, efficient and ecofriendly (3E concept).
\end{abstract}

Keywords: Honeycomb Monolith; Mo (VI)/ZrO $;$; Salicylate Esters; 3E Concept; Transesterification

\section{Introduction}

Metal oxide based solid acids as heterogeneous catalysts are extremely useful in many large-volume applications, especially in the production of fine and specialty chemicals as well as in the petrochemical industry [1,2]. Among metal oxides, zirconia $\left(\mathrm{ZrO}_{2}\right)$ is a versatile oxide used as a catalyst as well as a catalyst support and promisingly has been employed in many industrially important organic transformations. Zirconia based solid acids such as $\mathrm{VO}_{x} / \mathrm{ZrO}_{2}, \mathrm{MoO}_{x} / \mathrm{ZrO}_{2} \& \mathrm{WO}_{x} / \mathrm{ZrO}_{2}$ have been synthesized and used as catalysts in a few liquid \& vapor phase reactions [3-5]. Though these zirconia based solid acid are superior catalysts and free form deactivation, they are less explored for organic synthesis [6].

Cordierite honeycomb monoliths as catalyst carriers have been used extensively in auto exhaust catalysis for gas phase reactions $[7,8]$ but least explored in liquid or vapor phase organic reactions. Hence, honeycomb monolith coated with solid acids such as zirconia and its modified forms would be a novel and extremely useful technique in liquid phase reactions for the production of fine and specialty chemicals as well as in the petrochemical industry.

\footnotetext{
*Corresponding author.
}

In the present article, work done on the synthesis of honeycomb coated with solid acids such as $\mathrm{ZrO}_{2}$ \& Mo (VI) $/ \mathrm{ZrO}_{2}$, their physico-chemical characterization and catalytic evaluation in liquid phase transesterification of methyl salicylate with various alcohols to synthesize their respective salicylate esters is described. Salicylate esters are industrially important and are mainly used in sun-tan lotions, antiseptic creams, etc.

\section{Experimental}

Zirconia $\left(\mathrm{ZrO}_{2}\right)$ and $\mathrm{Mo}(\mathrm{VI}) / \mathrm{ZrO}_{2}(\mathrm{MZ})$ with $6 \% \mathrm{Mo}(\mathrm{VI})$ were coated on honeycomb (HC) monoliths by impregnation method [8]. Typically, to coat $6 \% \mathrm{MZ}$ on a $\mathrm{HC}$, a dilute solution containing $5.4 \mathrm{~g}$ of zirconyl nitrate $\left[\mathrm{ZrO}\left(\mathrm{NO}_{3}\right)_{3} \cdot 8 \mathrm{H}_{2} \mathrm{O}\right] \& 0.1 \mathrm{~g}$ of ammonium molybdate $\left[\left(\mathrm{NH}_{4}\right)_{6} \mathrm{Mo}_{7} \mathrm{O}_{24} \cdot 4 \mathrm{H}_{2} \mathrm{O}\right]$ dissolved in $50 \mathrm{~mL}$ of deionised water was coated on a wash coated honeycomb by dipping and drying in a furnace pre-heated at $400^{\circ} \mathrm{C}$. The dipping and drying steps were repeated 8 to 10 times till $\sim 0.2 \mathrm{~g}$ of $6 \% \mathrm{MZ}$ is coated on the HC. The $\mathrm{HC}$ coated with $6 \% \mathrm{MZ}$ was calcined at $550^{\circ} \mathrm{C}$ for $5 \mathrm{~h}$ in a muffle furnace before its use as a catalyst. $\mathrm{ZrO}_{2}$ and $6 \% \mathrm{MZ}$ were also prepared in powder form by impregnation method.

Thus prepared catalysts (in both HC coated and powder forms) were analyzed for their total surface acidity by 
$\mathrm{NH}_{3}$-TPD, crystallinity by powder XRD and morphology by SEM techniques.

The catalytic activity of all the catalysts used in the present study was determined in liquid phase transesterification of methyl salicylate (MS) with alcohols such as ethanol, iso-propanol, iso-butanol, iso-pentanol, cyclohexanol \& benzyl alcohol to synthesize their respective salicylate esters. The transesterification was carried out in a batch reactor.

\section{Results and Discussion}

The total surface acidity (TSA) values of $\mathrm{ZrO}_{2}$ and $6 \%$ MZ (both in HC coated and powder forms) are given in Table 1. Zirconia was found to be less acidic when compared to $6 \% \mathrm{MZ}$ indicating that the incorporation of Mo (VI) ions increases the number of acid sites on zirconia thereby increasing the TSA values of $6 \% \mathrm{MZ}$ [9].

The PXRD patterns of the HC coated with zirconia consisted of peaks corresponding to both tetragonal $(T)$ and monoclinic $(M)$ phases (Figure 1). However, PXRD patterns of $6 \% \mathrm{MZ}$ consisted of only peaks corresponding to tetragonal phase and the peaks corresponding to monoclinic phase are absent. The PXRD patterns of $\mathrm{ZrO}_{2}$ and $6 \% \mathrm{MZ}$ in powder form were found to be similar to that of the PXRD patterns of their HC coated forms.

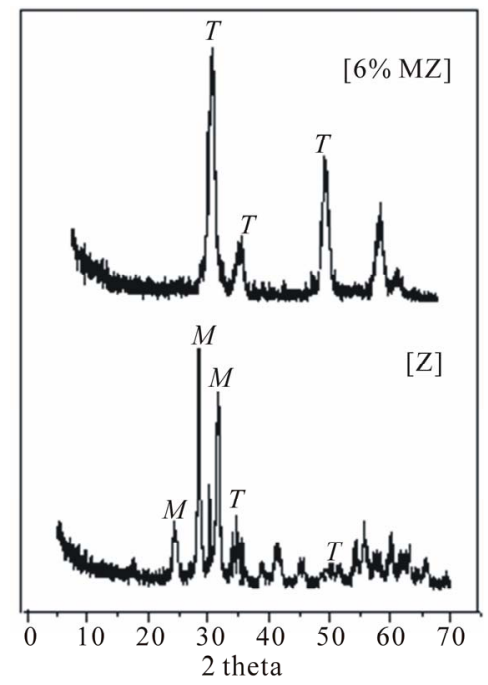

Figure 1. PXRD patterns of $\mathrm{ZrO}_{2}[\mathrm{Z}] \& 6 \% \mathrm{MZ}$.

Table 1. Total surface acidity (TSA in mmols/g) values of catalysts.

\begin{tabular}{cc}
\hline Catalyst & TSA \\
\hline $\mathrm{ZrO}_{2}(H C)$ & 0.42 \\
$\mathrm{ZrO}_{2}($ Powder $)$ & 0.40 \\
$6 \% \mathrm{MZ}($ HC) & 1.46 \\
$6 \% \mathrm{MZ}($ Powder $)$ & 1.38 \\
\hline
\end{tabular}

The information obtained from SEM images (Figure 2) of $6 \% \mathrm{MZ}$ i.e., structures sticking to the surface of the $\mathrm{HC}$ indicated that the method used for coating the catalytic material on the honeycomb was suitable enough to obtain adherent coating of the catalytic material (MZ).

Transesterification of methyl salicylate (MS) with different alcohols $(\mathrm{R})$ was carried out by taking MS: R ratio of 2:1 and the results are presented in Table 2. Since transesterification is a reversible reaction, excess of MS favors forward reaction leading to the formation of the desired product.

A correlation between the total surface acidity, PXRD phase and the catalytic activity of the catalyst was observed. $6 \% \mathrm{MZ}$ which possessed higher total surface acidity and also consisted of catalytically more active tetragonal phase [10] showed higher yield of salicylate esters when compared to $\mathrm{ZrO}_{2}$ catalyst (Table 2). Both $\mathrm{ZrO}_{2}$ and $6 \% \mathrm{MZ}$ were $100 \%$ selective towards the formation of salicylate esters.

Among different alcohols, since $i$-propanol and cyclohexanol are secondary alcohols they showed very less

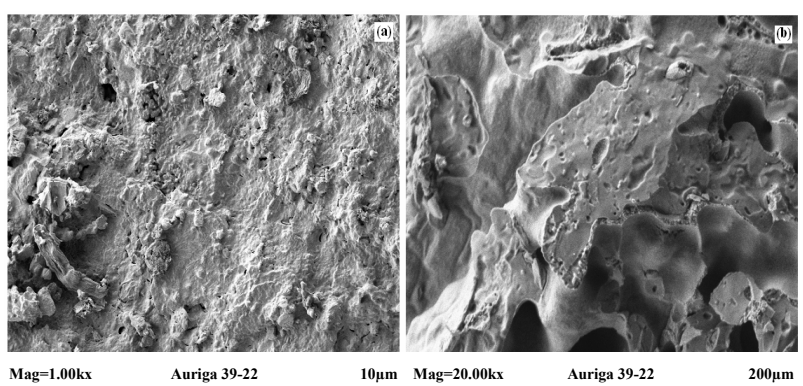

Figure 2. SEM pictures of honeycomb coated with $6 \% \mathrm{MZ}$; (a) Lower magnification; (b) Higher magnification.

Table 2. Transesterification of methyl salicylate with different alcohols over $\mathrm{ZrO}_{2}$ and $6 \% \mathrm{MZ}$ [Reaction conditions: Molar ratio of methyl salicylate: alcohol $(R)=2: 1$; reaction temperature $=$ refluxing temperature; catalyst weight $=\sim 0.2$ g of $\mathrm{ZrO}_{2}$ or $6 \% \mathrm{MZ}$; reaction time $=4 \mathrm{~h}$ ].

\begin{tabular}{|c|c|c|c|}
\hline \multirow[t]{2}{*}{ Alcohol (R) } & \multirow{2}{*}{$\begin{array}{l}\text { Salicylate } \\
\text { ester formed }\end{array}$} & $\begin{array}{c}\text { Yield }(\%) \\
\text { of salicylate } \\
\text { ester } \\
\end{array}$ & $\begin{array}{c}\text { Yield (\%) of } \\
\text { salicylate ester }\end{array}$ \\
\hline & & $6 \% \mathrm{MZ}(H C)$ & $\begin{array}{c}6 \% \mathrm{MZ} \\
\text { (Powder) }\end{array}$ \\
\hline Ethyl alcohol & Ethyl salicylate & $94(49)$ & $42(19)$ \\
\hline$i$-propanol & $i$-propyl salicylate & $03(00)$ & $00(00)$ \\
\hline$i$-butanol & $i$-butyl salicylate & $93(46)$ & $39(16)$ \\
\hline$i$-pentanol & $i$-pentyl salicylate & $81(34)$ & $35(11)$ \\
\hline Cyclohexanol & $\begin{array}{l}\text { Cyclohexyl } \\
\text { salicylate }\end{array}$ & $05(00)$ & $00(00)$ \\
\hline Benzyl alcohol & Benzyl salicylate & $85(41)$ & $35(12)$ \\
\hline
\end{tabular}

Note: Numbers in the parentheses (Columns $3 \& 4$ ) refer to the yield of salicylate esters over $\mathrm{ZrO}_{2}$ catalyst. 
yield due to more steric hindrance compared to primary alcohols.

When the catalytic activity of $0.2 \mathrm{~g} 6 \% \mathrm{MZ}$ (in powder form) and $6 \% \mathrm{MZ}$ (HC coated) were compared, even though same amount of the catalyst $(\sim 0.2 \mathrm{~g})$ was used in powder as well as in $\mathrm{HC}$ form, a $\sim 2$ fold increase in the yield of salicylate esters was observed over $\mathrm{HC}$ coated form of the catalyst. This can be attributed to the higher geometric surface area of the honeycomb catalyst [8]. Further, when the reusability of $6 \% \mathrm{MZ}$ in these two forms was checked, it was observed that the rate of decrease in the catalytic activity in powder form of the catalyst was more compared to its $\mathrm{HC}$ coated form.

\section{Conclusion}

In general, the solid acids coated on cordierite honeycomb monoliths are very efficient, economical, eco-friendly (3E concept) and novel catalysts for organic synthesis. These honeycomb catalysts are easy to prepare, efficient, economical, easy to use, easily recoverable, easily regenerable and re-usable. Therefore, solid acids coated on honeycomb are more advantageous than in their powder form. Honeycomb monolith coated with $\mathrm{Mo}(\mathrm{VI}) / \mathrm{ZrO}_{2}$ can especially be an excellent catalyst for transesterification to synthesize industrially important salicylate esters.

\section{Acknowledgements}

The corresponding author is thankful to DST, New Delhi for funding. The authors are thankful to the authorities of University of Malaya for SEM analysis, Department of Chemistry, St. Josephs College, Bangalore for PXRD analysis and IITM, Chennai for $\mathrm{NH}_{3}$-TPD analysis.

\section{REFERENCES}

[1] J. Otera, "Transesterification," Journal of Chemical Reviews, Vol. 93, No. 4, 1993, pp. 1449-1470. doi:10.1021/cr00020a004

[2] A. Corma, S. Ibora, S. Miquel, J. J. Primo and J. J. Catal,
"Catalysts for the Production of Fine Chemicals: Production of Food Emulsifiers, Monoglycerides, by Glycerolysis of Fats with Solid Base Catalysts," Journal of Catalysis, Vol. 173, No. 2, 1998, pp. 315-321. doi:10.1006/jcat.1997.1930

[3] B. M. Reddy and M. K. Patil, "Organic Syntheses and Transformations Catalyzed by Sulfated Zirconia," Journal of Chemical Reviews, Vol. 109, No. 6, 2009, pp. 2185-2208. doi:10.1021/cr900008m

[4] X. Song and A. Sayari, "Sulfated Zirconia-Based Strong Solid-Acid Catalysts: Recent Progress," Catalysis Reviews: Science and Engineering, Vol. 38, No. 3, 1996, pp. 329-412. doi:10.1080/01614949608006462

[5] G. D. Yadav and J. J. Nair, "Sulfated Zirconia and Its Modified Versions as Promising Catalysts for Industrial Processes," Microporous and Mesoporous Materials, Vol. 33, No. 1-3, 1999, pp. 1-48. doi:10.1016/S1387-1811(99)00147-X

[6] M. Hino and K. Arata, "Synthesis of Solid Superacid Catalyst with Acid Strength Ho <-16.04," Chemical Communications, Vol. 18, 1980, p. 851.

[7] K. C. Patil, M. S. Hegde, T. Rattan and H. T. Aruna, "Chemistry of Nano Crystalline Oxide Materials, Combustion Synthesis, Properties and Applications," World Scientific Publishing Pvt. Ltd, Singapore City, 2008.

[8] T. A. Nijhuis, M. T. Kreutzer, A. C. J. Romijn, F. Kapteijn and J. A. Moulijn, "Monolithic Catalysts as Efficient ThreePhase Reactors," Chemical Engineering Science, Vol. 56, No. 3, 2001, pp. 823-829. doi:10.1016/S0009-2509(00)00294-3

[9] S. Z. M. Shamshuddin, M. S. Sundar, N. T. Venkatesh, G. Vatsalya and M. Senthilkumar, "Synthesis, Characterization and Catalytic Activity Studies on Cordierite Honeycomb Coated with $\mathrm{ZrO}_{2}$ Based Solid Super Acids," Comptes Rendus Chimie, Vol. 15, No. 9, 2012, pp. 799-807. doi:10.1016/j.crci.2012.05.020

[10] S. Z. M. Shamshuddin and N. Nagaraju, "Liquid Phase Transesterification of Methyl Salicylate and Phenol over Solid Acids: Kinetic Studies," Journal of Molecular Catalysis A: Chemical, Vol. 273, No. 1-2, 2007, pp. 55-63. doi:10.1016/j.molcata.2007.03.066 